\title{
Student Enrollment, Practitioner Diversity, and Patient Outcomes: Another Challenge for Educators
}

For the past several years, respiratory care education has been a source of heated debate resulting from publication of the "2015 and Beyond" recommendations ${ }^{1-3}$ and more recently by the general discussion of the decision to withdraw Policy 13 by the Tripartite. ${ }^{4}$ When these types of serious discussions take place in a healthy manner and include all stakeholders, the result can be moderate corrections in the direction of the profession, and ultimately, these peer-driven critiques ensure our profession's place in the future of the health-care delivery system.

\section{See the Original Study on Page 1817}

Today's workforce and, more importantly, today's patients do not represent the workforce and patient population that will be present a decade from now. Additionally, evolution of practice throughout the workforce is a lengthy process. One publication suggests that the amount of time it takes published research to change practice is no less than 17 years. ${ }^{5}$ Because of this, employers and monitors of health-care delivery need to speculate far ahead to provide the best care available.

In this issue of RespiRatory CARE, Becker and Nguyen ${ }^{6}$ identify another issue ripe for debate among all health-care education programs. They explore the demographics and ethnic diversity accompanying entry-level associate and baccalaureate education. What they found is a situation typical across all health-care provider fields of study and professional practice. There are relatively few minority health-care students or practicing providers. Unfortunately, this problem is not new and is considered to have always been the case. ${ }^{7,8}$ Interestingly, Becker and Nguyen found comparable demographic patterns in current college enrollment at both the associate and baccalaureate degree levels. This suggests that changes to entry-level require-

Dr Joyner has disclosed no conflicts of interest.

Correspondence: Robert L Joyner Jr PhD RRT-ACCS FAARC, Respiratory Therapy Program, DH 312/Department of Health Sciences, Salisbury University, 1101 Camden Avenue, Salisbury, MD 21801. E-mail: rljoyner@salisbury.edu.

DOI: $10.4187 /$ respcare. 03828 ments as recommended in the "2015 and Beyond" documents would not improve the ethnic disparity that currently exists. At each level of education, there are limited numbers of minority students whose demographics do not mirror the population demographics of the United States. Correspondingly, members of minority populations are more likely to receive a lower quality of care, experience higher rates of illness and disability, and die at a younger age than whites. ${ }^{89}$ A specific example of this is the higher rate of asthma and asthma-related morbidity and mortality in African-Americans in the United States compared with whites. ${ }^{10}$ One study found that closing the black-white mortality gap would eliminate a startling 83,000 excess deaths per year among African-Americans. ${ }^{11}$

A number of national and international organizations, including the Institute of Medicine and Physicians for Human Rights, believe that a diverse workforce that mirrors the nation's racial and ethnic patterns is a key to achieving excellence in health care. ${ }^{12}$ The rationale for increased diversity in the health-care workforce is that it will improve the overall health of the nation by creating a system that has a better grasp on ethnic, cultural, and language barriers to quality health care. Reaching toward a more diverse population of health-care providers will ultimately result in a generation of respiratory therapists better prepared to provide culturally sensitive and population-directed patient care. ${ }^{13}$ This is congruent with the longstanding goal of the United States government to assemble a health-care workforce reflecting the United States population's diversity. ${ }^{14}$

Becker and Nguyen ${ }^{6}$ should be applauded for bringing the issue of racial and ethnic disparities in respiratory care to the forefront. While we are debating the issue of entrylevel requirements for graduate respiratory therapists, finding strategies to reduce racial and ethnic disparities as a way to improve the respiratory health of our patients should also be added to the list of goals for the future of respiratory care education and workforce development.

Robert L Joyner Jr PhD RRT-ACCS FAARC Respiratory Therapy Program Department of Health Sciences Salisbury University Salisbury, Maryland 


\section{Student Enrollment, Practitioner Diversity, and Patient Outcomes}

\section{REFERENCES}

1. Kacmarek RM, Durbin CG, Barnes TA, Kageler WV, Walton JR, O'Neil EH. Creating a vision for respiratory care in 2015 and beyond. Respir Care 2009;54(3):375-389.

2. Barnes TA, Gale DD, Kacmarek RM, Kageler WV. Competencies needed by graduate respiratory therapists in 2015 and beyond. Respir Care 2010;55(5):601-616.

3. Barnes TA, Kacmarek RM, Kageler WV, Morris MJ, Durbin CG Jr. Transitioning the respiratory therapy workforce for 2015 and beyond. Respir Care 2011;56(5):681-690.

4. Committee on the Accreditation for Respiratory Care, National Board for Respiratory Care, American Association for Respiratory Care. Joint announcement regarding Policy 13. https://www.aarc.org/headlines/14/05/policy_13/announcement.pdf. Accessed October 17, 2014.

5. Morris ZS, Wooding S, Grant J. The answer is 17 years, what is the question: understanding time lags in translational research. J R Soc Med 2011;104(12):510-520.

6. Becker EA, Nguyen XT. The current impact of entry-level associate and baccalaureate degree education on the diversity of respiratory therapists. Respir Care 2014;59(12):1817-1824.

7. Smith DB. Health care divided: race and healing a nation. Ann Arbor, Michigan: University of Michigan Press; 1999.

8. Byrd WM, Clayton L. An American health dilemma: race, medicine, and health care in the United States. New York: Routledge; 2002.
9. Institute of Medicine (IOM). Unequal treatment: confronting racial and ethnic disparities in health care. Washington, DC: The National Academies Press; 2003.

10. Silvers SK, Lang DM. Asthma in African Americans: what can we do about the higher rates of disease? Cleve Clin J Med 2012;79(3): 193-201.

11. Satcher D, Fryer GE Jr, McCann J, Troutman A, Woolf SH, Rust G. What if we were equal? A comparison of the black-white mortality gap in 1960 and 2000. Health Affairs 2005;24(2):459464.

12. Sullivan LW. Missing persons: minorities in the health professions, a report of the Sullivan Commission on Diversity in the Healthcare Workforce. 2004. http://www.aacn.nche.edu/media-relations/ SullivanReport.pdf. Accessed October 22, 2014.

13. Physicians for Human Rights. The right to equal treatment: an action plan to end racial and ethnic disparities in clinical diagnosis and treatment in the United States. 2003. http://www.paeaonline.org/ index.php?ht=a/GetDocumentAction/i/135605. Accessed October 22, 2014.

14. United States Department of Health and Human Services. Pipeline programs to improve racial and ethnic diversity in the health professions: an inventory of federal programs, assessment of evaluation approaches, and critical review of the research literature. 2009. http://bhpr.hrsa.gov/healthworkforce/reports/pipelineprogdiversity. pdf. Accessed October 22, 2014. 